\title{
Trends in Smart Manufacturing: Role of Humans and Industrial Robots in Smart Factories
}

\author{
Linn D. Evjemo ${ }^{1} \cdot$ Tone Gjerstad $^{2}$ • Esten I. Grøtli ${ }^{3} \cdot$ Gabor Sziebig $^{2}$ \\ Published online: 18 April 2020 \\ (C) The Author(s) 2020
}

\begin{abstract}
Purpose of Review This paper provides an overview of the role of humans and robots in smart factories, their connection to Industry 4.0 , and which progress they make when it comes to related technologies.

Recent Findings The current study shows that a decade was not enough to provide a reference implementation or application of Industry 4.0, like smart factories. In 2011, Industry 4.0 was mentioned for the first time in the scientific community. Industry 4.0 arrived with many new enabling technologies and buzzwords, e.g., Internet of Things (IoT), Cyber-Physical Systems (CPS), and Digital Twins (DT).

Summary This paper first defines smart factories and smart manufacturing in relation to the role of humans and robots. Followed by an overview of selected technologies in smart factories. Concluded by future prospects and its' relation to smart manufacturing.
\end{abstract}

Keywords Industry $4.0 \cdot$ Smart manufacturing $\cdot$ Human-robot collaboration $\cdot$ Factories of future $\cdot$ Automation

\section{Introduction}

"The factory of the future will have two employees: a human and a dog. The task of the human will be to feed the dog. The dog will have the task to dissuade the human to touch the automated systems." as said by Warren G. Bennis in 2016. This quote describes the expectations, perception, and faith in the implementation of Industry 4.0. Tremendous effort has been put in order to realize the concept of Industry 4.0 and

This article is part of the Topical Collection on Robotics in Manufacturing

Gabor Sziebig

gabor.sziebig@sintef.no

Linn D. Evjemo

linn.d.evjemo@ntnu.no

Tone Gjerstad

tone.b.gjerstad@sintef.no

Esten I. Grøtli

esteningar.grotli@sintef.no

1 Norwegian University of Science and Technology, Trondheim, Norway

2 SINTEF Manufacturing, Trondheim, Norway

3 SINTEF Digital, Trondheim, Norway its' equivalents in the different continents (Europe, Industry 4.0 [1]; China, made in China 2025 [2]; the USA, advanced manufacturing [3]; Japan, super smart society [4]).

The main challenge and limitation in all cases is the balance between human and automation [5]. Through automation, artificial intelligence and novel sensors, Industry 4.0 will create a new manufacturing and distribution process. By this, processes are digitized, robots are carrying out work (or collaborate), and the human is in charge to supervise manufacturing and other quality ensuring processes. Places, where such manufacturing is executed, are also called smart factories. These are smart in a way that their production machines are permanently coordinated with each other and they self-control while ensuring the highest efficiency (smart manufacturing).

In order to achieve a high level of automation combined with flexibility as introduced above, human skills must be described and transferred to automated machines (e.g., industrial robots). If this is not possible, proper collaboration between human and machine is needed [6]. Solutions so far focus on limited applications and do not provide a complete system [7]. Smart factories, as also presented in this article, do not exit yet [8] due to the social impact [9].

The article first introduces the concept of smart manufacturing and its connection to smart factories, then the role of humans (human factor) and industrial robots in smart factories will be 
described. How new manufacturing and automation tools change the smart factories will be described afterwards, as well as the future of smart manufacturing and smart factories.

\section{Definition of Smart Manufacturing and Smart Factories}

Smart manufacturing can be defined as an intelligent manufacturing process (e.g., production with a $\mathrm{CNC}$ machine or a welding operation with an industrial robot) composed of a physical representation, connected to its digital twin through a digital thread. The digital thread allows the physical world to interact or exchange information (with the use of sensors, actuators) between its virtual representation and the digital twin. The digital twin is capable to predict, analyze, and support the manufacturing process with expert knowledge. Intelligent (smart) manufacturing is given great opportunities with all the new technologies such as cloud computing, Internet of things, big data analysis, and artificial intelligence. These technologies are used to obtain real-time information, extract knowledge, and make well-informed decisions. According to [10], artificial intelligence and deep learning may be used to solve the challenges of uncertainties and complexities of the manufacturing, by predicting future problems or failures before they occur in real life.Connection of virtual and physical worlds through Cyber-Physical Systems (CPS), resulting in the integration of manufacturing processes and business processes, are paving the way toward smart factories. In smart factories, the products, resources and processes are decided and controlled by CPS. This setup provides quality, time, resource, and cost advantages in comparison with classical production systems [11]. Figure 1 shows a sketch of a smart factory.
Liu et al. [12] present a shop floor decision-making support and cloud-based analytics provided in Cyber-Physical Machine Tool (CPMT) to improve the efficiency of machining tools and processes, feedback loops, and autonomous feedback control. A CPMT Platform based on OPC-UA and MTConnect demonstrates enabling interoperable data communication between different machine tools and software applications for a CNC machine.

While Cyber-Physical Machine Tools are connected to the real environment, the technology digital twins are still in an early, theoretical phase. Several cases are developed and evaluated to support the design of digital twin models [8]. Digitalization in manufacturing is seen as an opportunity to achieve higher levels of productivity. A virtual and computerized part of a physical production system is often called a digital twin. The use of digital technology enables the analysis of a large amount of data, the evaluation of selected information and test of alternative solutions before a decision is made or an implementation is started. The technology is mostly used in production planning and control but is also suitable for maintenance planning and control $[13 \bullet \bullet]$.

\section{Humans in Smart Factories}

The field of human-robot collaboration (HRC) has received much attention lately. There are many research and industrial laboratories around the world experimenting with collaboration between humans and robots $[14,15 \cdot]$. One of the main motivations for this is the more widespread usage of robots (industrial-, service-, mobile-robots) [16, 17]. Robots are thought to be a solution for many of the social challenges that today's society is facing (e.g., care taking of elderly people, replacing humans in dangerous/monotonous work).

Fig. 1 Smart factory pipeline

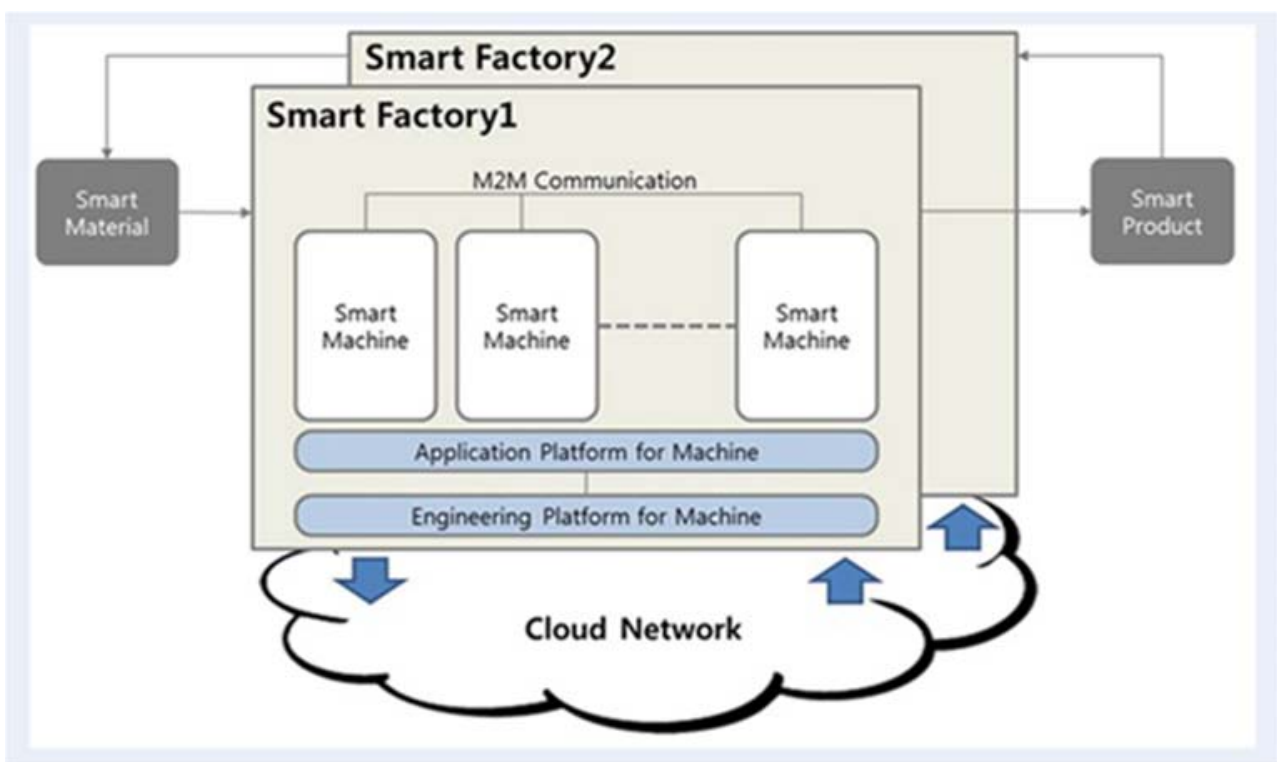


The paradigm related to human-robot collaboration is changing from the separate human-robot (past) to improved human access to robots (present) and close human-robot interaction (future). One major problem for the introduction of robots especially in unstructured environments (meaning outside separated, fenced zones) is the missing possibility to rely on dependable sensors. A robot needs sensor data for, e.g., reactive planning, motion/force control, visual servoing, fault diagnosis, and monitoring of safety levels. If the HRC system is planned for unstructured environments with unpredictable movements of persons, HRC should be equipped with a versatile sensor system, including range, proximity, touch, vision, sound, temperature, and so on. The selection, the arrangement, the number of sensors, and their reliability contribute to the measure of dependability of a manipulator for interaction tasks [18].

Further increase of the flexibility of automated production processes will be reached by introducing human-robot interaction. Processes will be improved by complementing the human cognitive and sensorimotor skills with robot precision and fatigue-free work of the robot. Such solutions do not require a safety zone around the robots, or the safety zones will be smaller than for the traditional robots. A key factor for successful HRC is represented by intuitive design of the interaction and control of the robot as well as the task allocation between the operator and robot.

Human-robot interaction is at this stage not validated for industrial use [19].

\section{Robots in Smart Factories}

In smart factories, robots are embedded with sensors to allow for human-robot collaboration in a safe work space. The so called collaborative robots (cobots) have several advantages compared with traditional industrial robots. These robots are safe for humans and can create space required by traditional robots, which require guarding fence. The safety mechanisms can be a combination of several technologies: the use of proximity sensors to slow down the robot when humans come near; force limitations in order to minimize risks to humans or the environment; and the human intent and maneuver accordingly. Beyond these mechanisms to ensure safety, different levels of human-robot collaboration can be implemented. Humans perform the tasks requiring the highest level of dexterity, while robots do repetitive, heavy, and dull tasks.

A collaborative robot is defined in standard ISO 10218-2 as follows: A robot designed for direct interaction with a human within a defined collaborative workspace, i.e., workspace within the safeguarded space where the robot and human can perform tasks simultaneously during production operation, as shown in Figure 2. The idea is, basically, that robots do not hurt a person and the means to protect a person are controlled force and speed, separation monitoring, hand-guiding, and a safety-rated monitored stop.

There are of course other aspects beyond safety which distinguishes how robots are being used in smart factories. Vision and CAD aided robot planning and control can help avoid time-consuming manual programming of robots, see, e.g., $[20,21]$. Learning by demonstration can also relieve for the need for manual programming, e.g., through the use of dynamic motion primitives used to parameterize robotic motions [22]. This can lead to efficient production adjustments in the case of small batches of products with minor variations in both shape and size.

\section{Autonomous Ground Vehicles}

AGVs can play an important role when it comes to logistics in smart factories. Efficient transport inside, to or from factories, can free up humans to do more rewarding tasks or free up space from more permanent ways of logistic handling such as conveyor belts. The latter will also give more flexibility if the interior of the factory needs to be changed, for instance, due to changes in production $[23,24]$.

\section{Sensor Integration}

The fusion of the sensory information coming from multiple sources could help in providing a coherent and reliable description of the world surrounding the robot. In general, it is required to integrate sensor information based on approximate models of the environment only. Data fusion is particularly important when monitoring contacts, e.g., for selecting impedance parameters or for determining the most dangerous "control points" on the robot to be driven away from a human with higher priority. There are a lot of sensors available for HRC systems. However, there has been little work on achieving the fusion of contact and visual information.

Close human-robot collaboration with advanced safety sensors may support speed and separation monitoring and safety-rated monitored stop modes. These might include close proximity sensors, such as pan/tilt/zoom cameras, stereo cameras, depth cameras, projection based-systems [25], and audio/video feedback systems. A better fit for traditional robots (large, high speed, high payload) can be achieved by compliment power and force limiting functions (PFL robots). Sensors for distance interaction include pan/tilt/zoom cameras, stereo cameras, projection-based systems, 3D Lidar, audio/ video feedback systems, and certified safety sensors. HRC sensors can also include force/torque sensors or proximity sensors integrated into grippers [26]. 
Fig. 2 Human-robot collaboration in a collaborative workspace

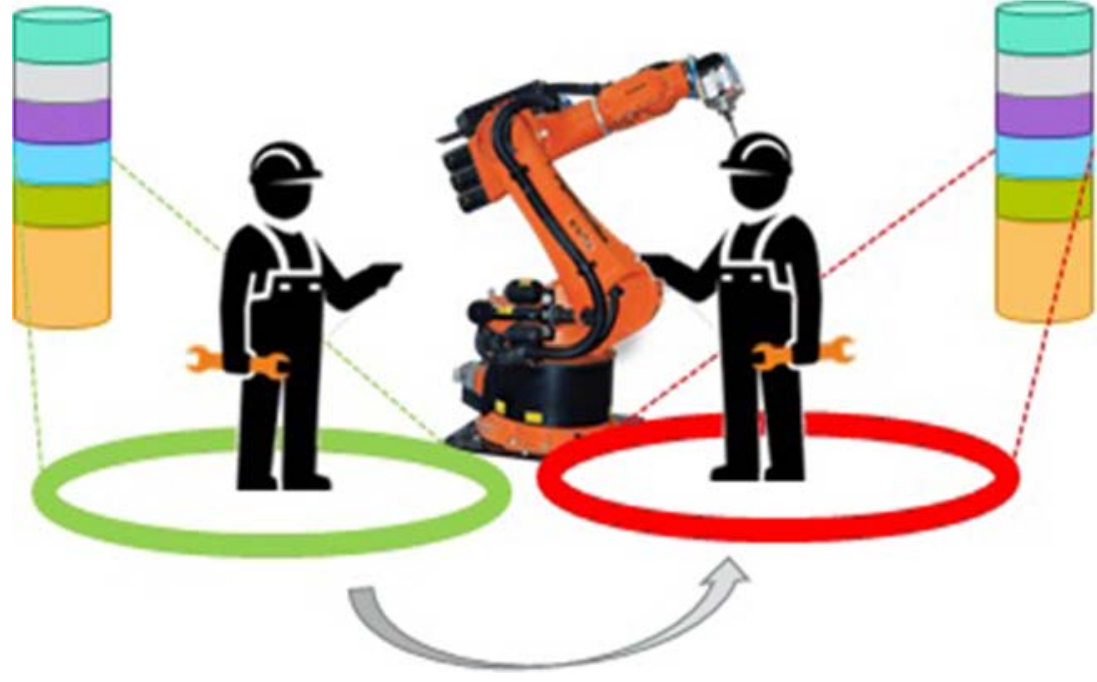

\section{Manufacturing in Smart Factories}

Manufacturing in smart factories has a great potential in case of personalized products, because of the combination of lowcost prices, like in mass production, and still having a minimum amount of labor for customization. One of the possibilities lies within additive manufacturing [27], where many products could be manufactured at the client's premises and on demand, without loss of transportation time or logistic overhead costs. This will result in cost reduction for these products due to the fact that their customization time and cost is minimal compared with their manufacturing time.

\section{Additive Manufacturing by Robot}

The umbrella term additive manufacturing (AM) covers a variety of techniques for building up three-dimensional structures, often custom-made. Different methods of AM, such as 3D printing and rapid prototyping (RP), have evolved from creating simplified models that help visualize an end product to creating structures that work as end products themselves [28]. AM technology is still gaining momentum and is especially important for small companies and developers in order to easily create low-cost prototypes and custom-made parts [29].

It is mainly smaller parts and products that have been produced using AM technology. This is because most traditional methods for AM require the structure to be built "in-box," i.e., in a container of some kind within the AM apparatus. This in turn requires the $\mathrm{AM}$ machine to be larger than the structure it is producing, which has its natural limitations. However, this is gradually changing, as more and more projects have started looking into AM on a larger scale. Already, AM has been using in several housing projects, while the Dutch MX3Dproject has constructed a metal bridge solely through AM by robot manipulator [30].
Our research on large-scale AM focuses on metal structures, combining wire-arc additive manufacturing (WAAM) with a 6 degrees-of-freedom (DOF) robot manipulator. By combining the flexibility and large workspace of an industrial robot with material deposition, it would be possible to build larger structures. In 2016, students at Cranfield University demonstrated the potential of robotized WAAM when producing a $6 \mathrm{~m}$ long, $300 \mathrm{~kg}$ aluminum spar built in one piece with the university's $10 \mathrm{~m}$ robot rig for WAAM [31]. For this part, the team estimated a cost saving of about $70 \%$ compared with machining a similar part from a solid block. This project has been commercialized over the last few years, resulting in the company WAAM3D, which is working on delivering both small batch sizes and prototypes to be tested in industry [32]. In order to better take advantage of the large workspace and flexibility this gives us, our research also aims to move away from the strictly layer-wise approach of traditional methods for AM.

WAAM has the potential for a relatively high deposition rate for several $\mathrm{kg}$ of material per hour, and a great reduction in lead time compared with other methods [33], which is promising in a financial context. There are still some challenges related to the building process, such as starting and stopping the building process, which leads to distortions because of arc initiation and flame-out [34]. This might be solved by performing builds that are as continuous as possible, though this might lead to challenges in material properties related to residual stresses, or more superficial challenges such as changes in bead height due to an accumulation of heat. How much this would impact the final structure would of course mostly depend on the material. However, if it was possible to surveil the building process in order to adjust the heat input, etc. based on feedback, this would greatly improve the potential for WAAM when building structures on any scale.

Through experiments, the challenges related to intersections and corners when building in a semi-layer-wise manner 
have been investigated [35]. Building larger structures can be time consuming, so the builds have been done as continuously as possible, which again requires a balance between heat input from the welding process and the cooling of the structure.

A set-based control method that allows some freedom in the orientation of the tool has also been used in these experiments, tolerating that the orientation of the welding gun deviates within a chosen interval. This method can make the trajectory for the robot's end effector less demanding, and has previously been tested for spray painting [36]. In addition, this freedom in orientation means that material is mostly deposited while the welding-gun is not strictly vertical, which strongly differs from traditional bottom-up or top-down methods. Thin-walled, cylindrical structures were also built with a continuous height increase of the tool, as opposed to the traditional layer-by-layer approach [37].

One of the most interesting recent developments in largescale WAAM might be the beforementioned MX3D-project, which recently announced that they have printed a complete stainless-steel industrial robot arm, part by part, using WAAM combined with correctional machining. With continuous welding, they claim this build could be done in only four days [30]. The robot arm has not yet been assembled, but if the complete experiment is successful, this shows the promise of WAAM and AM in general as a way to effectively and affordably create customized parts both for prototyping and replacement.

As AM evolve away from the traditional in-box methods, there is potential for the products to be both larger and more complex. Bypassing the strictly layer-by-layer approach would remove the need for building support structures that must be removed in post-processing and make it possible to build structures with overhang. While most experiments with large-scale AM are presently done in-house, the natural next step will be to see how these methods can be utilized both on doing the builds on-site and adding material to existing structures. This could open new possibilities for repair work and modifications on structures that are hard to move.

Furthermore, not only structural freedom is possible by AM but also the use of novel materials (e.g., dissimilar: titanium and nickel alloys) is also possible. While WAAM is suitable for the creation of large-sized parts with medium complexity components, made with high-value materials since it creates a near net shape end results that only need final machining on high-tolerance surfaces. Today the aerospace industry is using WAAM for titanium and nickel alloys [38]. Norsk Titanium has delivered the first titanium additively manufactured component made via WAAM approved by the Federal Aviation Administration, as it was installed on the Boeing 787 Dreamliner [38]. The use of new materials or combining different materials creates possibilities for complex geometry with the needed material properties in the correct place of the part.
The combination of WAAM with laser metal deposition (LMD) creates possibilities for coating, cladding, or building complex and large geometries. The usage of dissimilar materials for LMD has been shown in industrial setting for years and, here, new materials and combination can give great possibilities for repairing and building complex parts. In [39] the possibility of dismissal material builds using copper on AISI $304 \mathrm{~L}$ steel is shown, but also the immiscible material combination like TiC-Ni shows the potential of multi-materials builds. The possibilities for new materials and new material combinations will give improved product properties as the material properties improve with the combination that AM gives with regard to the geometrical building freedom.

Another option is using Cold Metal Transfer (CMT) for welding dissimilar material as shown in [40], where an AlSi5 was used as weld filler for welding a magnesium alloy plate and an aluminum alloy plate together. This shows the possibility to use different and new materials for CMT AM. In [41] the CMT process, it was used to weld an aluminum alloy with zinc coated low carbon steel. The potential of dissimilar welding shows great potential for CMT in combination with WAAM, since the material combination and the development of coating and the repair of components can be achieved with materials that are using traditional manufacturing methods that are difficult to machine but have good material properties.

\section{Future of Smart Manufacturing and Smart Factories}

In the future, the synergy of the skills of robots and humans will be even more important in order to increase productivity and quality, while still maintaining sustainable working conditions and environment, health and safety (EHS) for humans. This will clearly motivate manufacturing scenarios, where humans and industrial automation devices are operating within the same working space, utilizing, mutually, the capabilities of each other.

During the last decades, the industrial robot has clearly demonstrated its capability to be the core component in industrial automation (Smart Factory), due to the fact that it provides an optimum of high working capacity and flexibility. By connecting the robot even closer to the human, in terms of direct collaboration or task sharing within the same working area, there is important potential for a strong synergy between the robots' and the humans' capability; thus, a very productive, user friendly, however, rapidly changeable system.

Smart factories will need novel solutions to create an open robot system with automatic transition between multiple safety modes. This enables an environment where the robot system can seamlessly adapt, i.e., switch from full automation to safe task sharing and direct collaboration within the robot's working area. 
The identified main achievements for upcoming smart factories are:

- An open workspace where the human and robot are capable of autonomy, collaborate on decisions, and actions needed to optimize their skills to accomplish a task.

- Shared autonomy including a collaborative workspace where tasks are scheduled between the human and robot; a collaborative robot sharing optimally its control in various degrees of freedom with a human.

- Improved flexibility, productivity, and EHS conditions for the human worker.

- A learning capability of the robot, by easy, natural communication with the human.

- A workspace without fences, to enable seamless and automatic transition between safety modes, according to the human risk for physical conflicts between the human and robot.

Particular attention will be needed to address the psychosocial aspects of human-robot collaboration and raising the acceptability of the new technology. Through analysis of the user-interaction scenarios, worker-specific aspects such as ergonomics, skills/expertise levels, safety, and comfort need to be taken into account.

Funding Information Open Access funding provided by SINTEF AS. The work reported in this paper was supported by the center for research-based innovation SFI Manufacturing in Norway, and is partially funded by the Research Council of Norway under contract number 237900 .

\section{Compliance with Ethical Standards}

Conflict of Interest The authors declare that they have no conflict of interest.

Human and Animal Rights and Informed Consent This article does not contain any studies with human or animal subjects performed by any of the authors.

Open Access This article is licensed under a Creative Commons Attribution 4.0 International License, which permits use, sharing, adaptation, distribution and reproduction in any medium or format, as long as you give appropriate credit to the original author(s) and the source, provide a link to the Creative Commons licence, and indicate if changes were made. The images or other third party material in this article are included in the article's Creative Commons licence, unless indicated otherwise in a credit line to the material. If material is not included in the article's Creative Commons licence and your intended use is not permitted by statutory regulation or exceeds the permitted use, you will need to obtain permission directly from the copyright holder. To view a copy of this licence, visit http://creativecommons.org/licenses/by/4.0/.

\section{References}

Papers of particular interest, published recently, have been highlighted as:

- Of importance

- Of major importance

1. Hankel M, Rexroth B. Industrie 4.0: the reference architectural model industrie 4.0 (rami 4.0). Die Elektroindustrie: ZVEI; 2015.

2. Kuo CC, Shyu JZ, Ding K. Industrial revitalization via industry 4.0 a comparative policy analysis among China, Germany and the USA. Global Transit. 2019;1:3-14. https://doi.org/10.1016/j.glt.2018.12. 001.

3. Anderson, A.: Report to the President on Ensuring American Leadership in Advanced Manufacturing. Executive office of the President (2011) Accessed 2019-02-16.

4. Fukuyama, M.: Society 5.0: aiming for a new human-centered society. Japan Spotlight pp. 47-50 (2018).

5. Braganca S, Costa E, Castellucci I, Arezes PM. A brief overview of the use of collaborative robots in Industry 4.0: human role and safety. Basel: Springer International Publishing; 2019. p. 641-50.

6. Sziebig G. Survey and planning of high-payload human-robot collaboration: multi-modal communication based on sensor fusion. In: Wang Y, Martinsen K, Yu T, Wang K, editors. Advanced manufacturing and automation IX. Singapore: Springer Singapore; 2020. p. 545-51.

7. Zeid A, Sundaram S, Moghaddam M, Kamarthi S, Marion T. Interoperability in smart manufacturing: research challenges. Machines. 2019;7(2):21.

8. Stark R, Fresemann C, Lindow K. Development and operation of digital twins for technical systems and services. CIRP Ann. 2019;68(1):129-32. https://doi.org/10.1016/j.cirp.2019.04.024.

9. Fischer, K., Jensen, L.C., Kirstein, F., Stabinger, S., Erkent, O ., Shukla, D., Piater, J.: The effects of social gaze in human-robot collaborative assembly. In: A. Tapus, E. Andr'e, J.C. Martin, F. Ferland, M. Ammi (eds.) Social robotics, pp. 204-213. Springer International Publishing, Cham (2015).

10. Wan L. From intelligence science to intelligent manufacturing. Engineering. 2019;5(4):615-8. https://doi.org/10.1016/j. eng.2019.04.011.

11. Bunse, B., Kagermann, H., Wahlster, W.: Industrie 4.0-smart manufacturing for the future. GTIA-Germany Trade and Invest $\mathrm{p}$. 40 (2013).

12. Liu C, Vengayil $\mathrm{H}, \mathrm{Lu} \mathrm{Y}, \mathrm{Xu} \mathrm{X}$. A cyber-physical machine tools platform using OPC-UA and MTconnect. J Manuf Syst. 2019;51: 61-74. https://doi.org/10.1016/j.jmsy.2019.04.006.

13.• Kritzinger, W., Karner, M., Traar, G., Henjes, J., Sihn, W.: Digital twin in manufacturing: a categorical literature review and classification. IFAC-PapersOnLine 51(11), 1016-1022 (2018). Describes the importance of digital twins in relation to smart factories. Concludes with the lack of real implementation.

14. Avalle G, De Pace F, Fornaro C, Manuri F, Sanna A. An augmented reality system to support fault visualization in industrial robotic tasks. IEEE Access. 2019;7:132343-59. https://doi.org/10.1109/ ACCESS.2019.2940887.

15. Matheson E, Minto R, Zampieri EG, Faccio M, Rosati G. Humanrobot collaboration in manufacturing applications: a review. Robotics. 2019;8(4):100 Highlights the major trends in application of robots in manufacturing. Assumes the spread of cobots will decline.

16. Oyekan JO, Hutabarat W, Tiwari A, Grech R, Aung MH, Mariani MP, et al. The effectiveness of virtual environments in developing collaborative strategies between industrial robots and humans. Robot Comput Integr Manuf. 2019;55:41-54. https://doi.org/10. 1016/j.rcim.2018.07.006. 
17. Robla-Gomez S, Becerra VM, Llata JR, Gonzalez-Sarabia E, TorreFerrero C, Perez-Oria J. Working together: a review on safe humanrobot collaboration in industrial environments. IEEE Access. 2017;5: 26754-73. https://doi.org/10.1109/ACCESS.2017.2773127.

18. Shu, B., Sziebig, G., Pieska, S.: Human-robot collaboration: task sharing through virtual reality. In: IECON 2018 - 44th Annual Conference of the IEEE Indus- trial Electronics Society, pp. 6040-6044 (2018). DOI https://doi.org/10.1109/IECON.2018.8591102

19. Petruck H, Nelles J, Faber M, Giese H, Geibel M, Mostert S, et al. Human- robot cooperation in manual assembly - interaction concepts for the future workplace. In: Chen J, editor. Advances in human factors in robots and unmanned systems. Cham: Springer International Publishing; 2020. p. 60-71.

20. Linnerud, A.S., Sandøy, R., Wetterwald, L.E.: Cad-based system for programming of robotic assembly processes with human-in-theloop. In: 2019 IEEE 28th International Symposium on Industrial Electronics (ISIE), pp. 2303-2308 (2019). DOI https://doi.org/10. 1109/ISIE.2019.8781385

21. Arbo, M.H., Pane, Y., Aertbelien, E., Decre, W.: A system architecture for constraint-based robotic assembly with cad information. In: 2018 IEEE 14th International Conference on Automation Science and Engineering (CASE), pp. 690-696 (2018).

22. Pastor, P., Hoffmann, H., Asfour, T., Schaal, S.: Learning and generalization of motor skills by learning from demonstration. In: 2009 IEEE International Conference on Robotics and Automation, pp. 763-768 (2009). DOI https://doi.org/10.1109/ROBOT.2009. 5152385

23. Luo Y, Duan Y, Li W, Pace P, Fortino G. Work-shop networks integration using mobile intelligence in smart factories. IEEE Commun Mag. 2018;56(2):68-75.

24. Mehami J, Nawi M, Zhong RY. Smart automated guided vehicles for manufacturing in the context of Industry 4.0. Procedia Manuf. 2018;26:1077-86.

25. Vogel, C., Poggendorf, M., Walter, C., Elkmann, N.: Towards safe physical human-robot collaboration: a projection-based safety system. In: $2011 \mathrm{IEEE} / \mathrm{RSJ}$ International Conference on Intelligent Robots and Systems, pp. 3355-3360 (2011). DOI https://doi.org/ 10.1109/IROS.2011.6094550

26. Bdiwi M, Pfeifer M, Sterzing A. A new strategy for ensuring human safety during various levels of interaction with industrial robots. CIRP Ann. 2017;66(1):453-6.

27. Pires, J.N., Azar, A.S.: Advances in robotics for additive/hybrid manufacturing: robot control, speech inter-face and path planning. Industrial Robot: An International Journal (2018).

28. Gibson, I., Rosen, D.W., Stucker, B.: Additive manufacturing technologies. Springer, Berlin (2010). DOI https://doi.org/10.1007/9781-4419-1120-9.

29. Ribeiro, F.M., Pires, J.N., Azar, A.S.: Implementation of a robot control architecture for additive manufacturing applications.
Industrial Robot: the international journal of robotics research and application (2019).

30. mx3d.com/"MX3D Bridge": Mx3d bridge (2015-2019). URL https://mx3d.com/projects/mx3d-bridge/. Accessed 2019-02-04.

31. Lathabai S.: Additive manufacturing of aluminium-based alloys and composites, Fundamentals of Aluminium Metallurgy, Woodhead Publishing, pp. 47-92 (2018) DOI https://doi.org/10. 1016/B978-0-08-102063-0.00002-3

32. waam3d.com/“WAAM3D Limited" (2018-2020). URL https:// waam3d.com/. Accessed 2020-03-03.

33. Williams SW, Martina F, Addison AC, Ding J, Pardal G, Colegrove P. Wire+ arc additive manufacturing. Mater Sci Technol. 2016;32(7):641-7.

34. Martina F, Mehnen J, Williams SW, Colegrove P, Wang F. Investigation of the benefits of plasma deposition for the additive layer manufacture of Ti-6Al-4V. J Mater Process Technol. 2012;212(6):1377-86.

35. Evjemo, L.D., Langelandsvik, G., Gravdahl, J.T.: Wire arc additive manufacturing by robot manipulator: towards creating complex geometries. In: 5th IFAC ICONS, Belfast, pp. 103-109. Elsevier (2019).

36. Moe S, Gravdahl JT, Pettersen KY. Set-based control for autonomous spray painting. IEEE Trans Autom Sci Eng. 2018;15(4): 1785-96. https://doi.org/10.1109/TASE.2018.2801382.

37. Evjemo, L.D., Moe, S., Gravdahl, J.T.: Robotised wire arc additive manufacturing using set-based control: experimental results. In: Proceedings of the 21st IFAC world congress (2020).

38. Rodrigues T. A., Duarte V., Miranda R. M., Santos T. G. and Oliveira J. P.: Current status and perspectives on wire and arc additive manufacturing (WAAM), materials 2019, 12(7), 1121, (2019) DOI https://doi.org/10.3390/ma12071121.

39. Brückner F., Riede M., Müller M. M., Marquardt F., Willner R., Seidel A., Lopez E., Leyens C. and Beyer E.: Enhanced manufacturing possibilities using multi-materials in laser metal deposition, In: 36th International Congress on Applications of Lasers \& Electro-Optics (ICALEO 2017), paper 1301 (2017).

40. Wang J, Feng JC, Wang YX. Microstructure of Al-Mg dissimilar weld made by cold metal transfer MIG welding, Materials Science and Technology. Mater Sci Technol. 2008;24(7):827-31. https:// doi.org/10.1179/174328408X278411.

41. Yang S, Zhang J, Lian J, Lei Y. Welding of aluminum alloy to zinc coated steel by cold metal transfer. Mater Des. 2013;49(2013):60212. https://doi.org/10.1016/j.matdes.2013.01.04.

Publisher's Note Springer Nature remains neutral with regard to jurisdictional claims in published maps and institutional affiliations. 